\title{
Principles of the therapy of bone infections in adult extremities
}

\author{
Are there any new developments?
}

\author{
Andreas Heinrich Tiemann · Gunther O. Hofmann
}

Received: 12 May 2008/Accepted: 4 June 2009/Published online: 3 July 2009

(C) Springer-Verlag 2009

\begin{abstract}
Septic diseases of the bone and immediately surrounding soft tissues can be differentiated into osteitis or osteomyelitis. Both are a most serious diagnosis in modern traumatology and orthopaedic surgery. The basis for treatment is a highly specific, problem-adapted therapy with a defined strategy, the paramount goal being to preserve the stable weightbearing bones, maintain a good mechanical axis with correctly working muscles and joints, and avoid permanent disability. "State-of-the-art" therapy of osteitis and osteomyelitis has two priorities: (a) Eradication of the infection; (b) Reconstruction of bone and soft tissue. Surgical treatment with resection of the affected bone segments and soft tissue, followed by reconstructive methods continues to be the main basic therapy, and is supported by local and systemic antibiotics and adjuvant methods such as hyperbaric oxygen. This article provides an overview of the diagnostic features and different surgical procedures as well as the current literature in order to reach the above named goals.
\end{abstract}

\footnotetext{
A. H. Tiemann $(\bowtie)$

Funktionsbereich Septische und Rekonstruktive Chirurgie, Klinik für Unfall- und Wiederherstellungschirurgie, BG-Kliniken Bergmannstrost Halle (Saale), Merseburger Str. 165, 06112 Halle, Germany e-mail: andreas.tiemann@bergmannstrost.de; susann.tiemann@t-online.de

G. O. Hofmann

Klinik für Unfall- und Wiederherstellungschirurgie, BG-Kliniken Bergmannstrost Halle (Saale), Merseburger Str. 165, 06112 Halle, Germany

G. O. Hofmann

Klinik für Unfall-, Hand- und Wiederherstellungschirurgie, Friedrich-Schiller Universität Jena, Erlanger Allee 101, 07747 Jena, Germany
}

Keywords Osteitis - Osteomyelitis - Surgical therapy

\section{Introduction}

The term osteitis refers to a bone infection mostly caused by bacteria that may lead to the complete destruction of the infected bone but also of the surrounding soft tissues. The medical literature usually makes no clear distinction between the terms osteitis and osteomyelitis. Using pathological and anatomical criteria the differentiation is between acute and chronic haematogenous osteomyelitis and acute and chronic exogenous (posttraumatic or postoperative) osteitis. The clinical and investigative findings of these diseases may be very similar and in their later stages it might be quite difficult to differentiate between the two.

Simon and Stille, and Schnettler and Steinau, define purulent and non-purulent osteitis. Based on clinical findings they further subdivide these terms into acute purulent, subacute purulent and chronic purulent osteitis [1, 2]. However, according to Hofmann, osteitis exists in two different forms [3]:

1. Acute postoperative osteitis This is a bacterial infection of the bone and surrounding soft tissues, that occurs within eight weeks of trauma or an operation.

2. Chronic osteitis If the infection occurs more than eight weeks after treatment or injury, it is defined as chronic osteitis.

In contrast, osteomyelitis refers to a primary infection of the bone marrow (myelitis) with subsequent affection of the cortical bone and periosteum. The main difference between osteitis and osteomyelitis is the way that the infection affects the bone. 
a. Centripetal: Osteitis

b. Centrifugal: Osteomyelitis

There are other staging systems, probably the best known being the University of Texas Medical Branch (UTMB) Clinical Staging System for Adult Osteomyelitis introduced by Cierny III et al. [4]. This classification focuses on the anatomical location in the bone affected by the infection and the immunological status of the patient. Although the system is over 20 years old, it still relevant as supported by a recent a reprint of the manuscript in 2003 .

Osteitis and osteomyelitis are among the most serious diseases of bones and surrounding soft tissues in terms of duration of the treatment and possible complications. Posttraumatic and postoperative osteitis has a serious negative impact on daily life for the injured patient. Very often it is the beginning of prolonged treatment with frequent operations and an unpredictable outcome.

Basic information on the incidence of osteomyelitis is poor. Statistics of the German Workers Compensation Insurance between 1993 and 2002 show an incidence of posttraumatic osteitis of $0.5 \%$ in closed and $2.6 \%$ in open fractures [5]. Coles and Gross examined the results of 895 fractures of the lower leg. They found superficial infections in $9 \%$ and osteitis in $0.4 \%$ after plate osteosynthesis; $2.9 \%$ superficial infections and $1 \%$ osteitis when reamed nails had been used, and $0.9 \%$ superficial infections and $1.5 \%$ osteitis when unreamed nails had been used [6]. In 1995 Ostermann et al. [7] analysed 1,085 open fractures. They found a $12 \%$ infection rate in the 240 fractures in which systemic antibiotics only were used but a $3.7 \%$ infection rate in 845 fractures in which they had used local antibiotics. In a similar study DeLong et al. [8] described an infection rate of $7 \%$. It is of interest that osteitis was found five or more months postoperatively in some studies [9].

The German Hospital Infection Surveillance System showed a $3.37 \%$ rate of infection (115 cases) following 4,843 osteosyntheses of fractures of the proximal femur. Thirty-six of these were classified as superficial infections. Ehrenberg et al. [10] reported bone infections in $2.14 \%$ and chronic osteitis in $0.43 \%$. Twenty years ago the mortality rate was $60 \%$ [Willensky] but now it is below $2 \%$ due to modern targeted therapy strategies [11].

The therapy of osteitis (osteomyelitis) is based on two principles, analogous to the treatment of malignant tumours:

1. Radical surgical eradication of the affected bone and soft tissue;

2. Adjuvant systemic and local chemotherapy (with antibiotics).

Also analogous to treatment for malignant tumours is the finding that complete recovery is not always possible even with these very aggressive and radical treatment methods. Osteitis (osteomyelitis) can be reduced to a nonsymptomatic state [12], but even after decades acute episodes may recur [13]. Nevertheless, modern therapeutic options have improved the incidence of a final symptomfree state to $80-87 \%$, depending on the type of injury and other predisposing factors [14].

Robson once called an infection as an "imbalance between germ and host" and implied that osteitis and osteomyelitis are due to predisposing factors, which according to Schmidt may be divided into the following groups [15]:

1. Endogenous factors: age over 65 years, obesity, nicotine and alcohol abuse, diabetes, vascular diseases, immunosuppressive therapy, cancer or general debility may lead to a suppression of the cellular and humoral resistance to infection [16].

2. Exogenous factors: bacterial invasion and soft tissue damage due to trauma or surgical manipulation are the main factors for the development of post-traumatic bone infection. After trauma the soft tissues are damaged and the skin no longer a barrier to bacterial invasion. This, in combination with an altered vascular situation, leads to ideal circumstances for bacterial multiplication and growth. Early infection may quickly involve the damaged bone; it is now recognised that bacterial invasion and secondary soft tissue damage during a surgical procedure lead more frequently to infection than does the primary injury with its bacterial contamination and soft tissue damage. Although $60-70 \%$ of open fractures are contaminated by bacteria, only a small proportion of these patients will develop osteitis [17]. However, in one series, about $62 \%$ of chronic bone infections were caused by trauma, $24 \%$ haematogenous in origin and the remaining $14 \%$ originated by spread from a chronic skin ulcer [18].

\section{Diagnostic principles}

Like many other infections or inflammatory diseases, bone infections do not always show pathognomonic signs. Nevertheless, pain is a main symptom. Fever may not always be present (although $85 \%$ of the patients do experience fevers) and the white blood count or the CRP may not be elevated [19].

$\mathrm{X}$-rays may not show any specific changes at the onset of the disease. In later stages, a sequestrum may be identified. Bone scans may show pathological changes as soon as $48 \mathrm{~h}$ after the onset of the infection but its specificity is less than $75 \%$ [20]. Due to the high dose of radiation, this method is no longer a standard procedure. Specific scintigraphic methods have the same problems as the bone scan [20]. They are not reliable in the detection of acute exogenous osteomyelitis as, after trauma, there is always the 
scintigraphic presence of a lesion and it is not possible to differentiate between fracture and bone infection. Specific monoclonal antibodies may provide additional information about inflammatory changes but it is difficult to distinguish between bone and soft tissues [21, 22].

Positron emission tomography (PET) scans are highly specific and can be very useful in the detection of osteomyelitic foci and the presence of chronic osteomyelitis [23, 24]. CT-scans are helpful in the detection of sequestra and abscesses. The sensitivity of the MRI is indisputable, being close to $100 \%$, but with specificity values between 60 and 95\% [25]. Although individual authors have reported false negative MRI results in the detection of osteomyelitis, negative MRI results will exclude the diagnosis "osteitis" [25]. The use of the "Inversion-Recovery-Technique" with MRI is important because it allows the detection of pathognomonic bone marrow oedema but this investigation is less helpful after surgery due to postoperative artefacts which superimpose over the osteomyelitic changes [5].

Ultrasonography is a standard examination technique for the localisation of pockets of liquid material in soft tissues. It also provides information on the size of the collection and its possible contents [26]. Aspiration of these liquid areas or biopsies may lead to the first diagnosis. Gramstaining may provide results after $45 \mathrm{~min}$ but definitive microbiological examination takes about $48 \mathrm{~h}$.

\section{Principles of therapy}

Until the beginning of the 1920 's, surgical treatment was the only treatment for osteomyelitis ("ubi pus ibi evacua"). Since then various means of the management have evolved and been reported in the medical literature. As with the treatment of malignant tumours, one has to distinguish between specific local and systemic therapies [27]. Together they should lead to:

1. Local and systemic eradication of the infection (or at least to an enduring non-symptomatic stage);

2. A stable limb with a normal mechanical axis;

3. Normal muscle action;

4. Normal joint function.

There are two issues to consider:

1. When is the correct time to intervene?

2. What is to be done (the type of surgery if needed; the use of antibiotics; and the method of antibiotic delivery)?

\section{Timing the intervention}

If there is a slightest suspicion of an infection after surgery for trauma, it is important that the wound should be dealt with surgically as soon as possible. The earlier revision surgery is performed, the greater the likelihood of eradication of the infection. Postoperative or posttraumatic wounds that are clinically and symptomatically suspicious should be surgically explored and revised early, especially if an osteosynthesis was performed and the implant may be involved in the infection. The "prophylactic" use of antibiotics in these cases probably prolongs the time period until surgical revision is ultimately performed. Additionally, the use of antibiotics in this instance is not prophylaxis but treatment of a surmised infection [28].

Local surgical treatment is based on five principles (Figs. 1, 2, 3, 4, 5, 6):

1. Local bone and soft tissue debridement

2. Stabilisation of the bone

3. Local antibiotic therapy

4. Reconstruction of the soft tissues

5. Reconstruction of the osseous defect

\section{Local debridement}

Suspicion is important, especially in post-operative bone infections, where clinical examination combined with suggestive results of investigations (either a rising of the CRP and white blood count, or an inadequate decrease of either) should lead to immediate revision of the wound [26] and radical removal of affected tissue. With bone tissue,

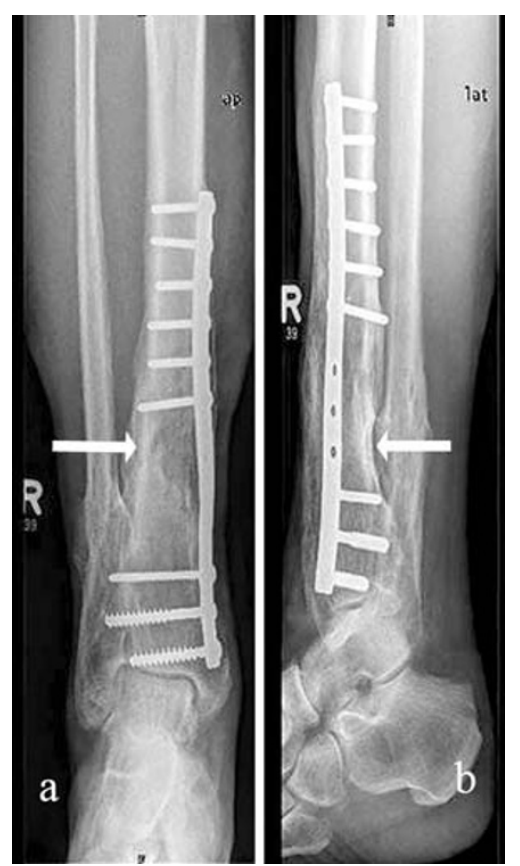

Fig. 1 Fifty-six-year-old male patient with chronic osteitis and fistula from a lower leg fracture. Osteosynthesis was performed in 1978. The preoperative X-ray shows the bone lesion under the osteosynthesis material and also a sequestrum $(\mathbf{a}, \mathbf{b})$ 

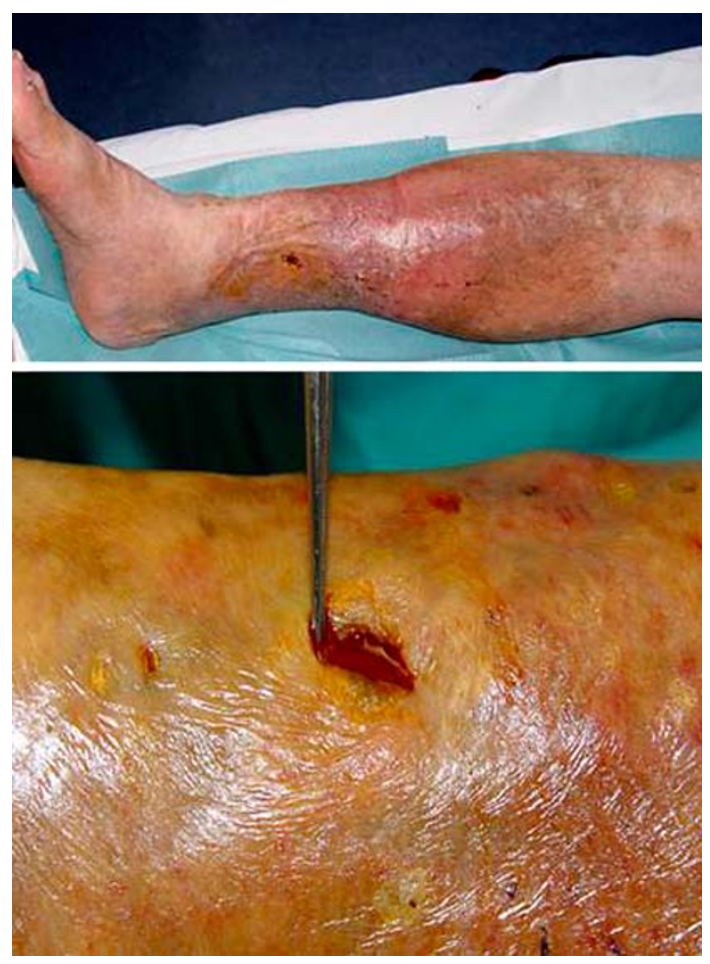

Fig. 2 Clinical findings at the day of admission

possible treatment extends from local debridement to resection of the infected area. Implanted osteosyntheses adjacent to an osteomyelitic focus are involved in the infection in almost $100 \%$ of cases and must be removed. Only if the diagnosis is made very early, the local infection not very extended and titanium implants were used, can the osteosynthesis material be left in situ [3] (see Fig. 7).
If intramedullary nailing was performed to stabilise the fracture, the nail must be removed, the medullary canal reamed and the reaming material examined microbiologically and histologically. Plates must also be removed and the area debrided. After surgical debridement of the osteomyelitic focus, extended irrigation with a pulsatile delivery system (3-5 $1 \mathrm{NaCl} 0.9 \%)$ is required.

Primary wound closure is not essential. Although coverage with intact soft tissues is a prerequisite for bone healing, it may be better to leave the wound open but covered by vacuum sealing techniques than to force a primary wound closure and so inflict damage to the local vascularity and produce further damage to the tissue. It is also possible to shorten the bone after resection of the osteomyelitic focus in order to protect the soft tissues and minimise the influence of tension on the vascular situation. This debridement technique is repeated every $48 \mathrm{~h}$ until the samples taken from the wound during operation do not show further bacterial growth and the clinical findings and the blood count (CRP, white cell count, etc.) approach normal.

\section{Stabilisation of the bone}

Bone stabilisation is usually accomplished by external fixators. The original osteosynthesis material is left in situ only in exceptional circumstances. The use of an external fixator has many advantages: it is relatively simple to apply; it provides good stability; and it does not produce further alteration of the soft tissues. The type of external fixator chosen (monolateral, circular, hybrid, etc.) is determined by the local demands of the problem being
Fig. 3 a Intraoperative situation. Exposure and removal of the osteosynthesis material. b Segmental resection of the tibia. The stabilising external fixator is already partially installed. c Resected bone material

Fig. 4 a Postoperative situation with completed external transport fixator. $\mathbf{b}$, $\mathbf{c}$ Postoperative X-ray of the proximal lower leg. It shows the transport corticotomy. d, e Postoperative X-ray of the distal lower leg. It shows the bone defect after tibial segment resection
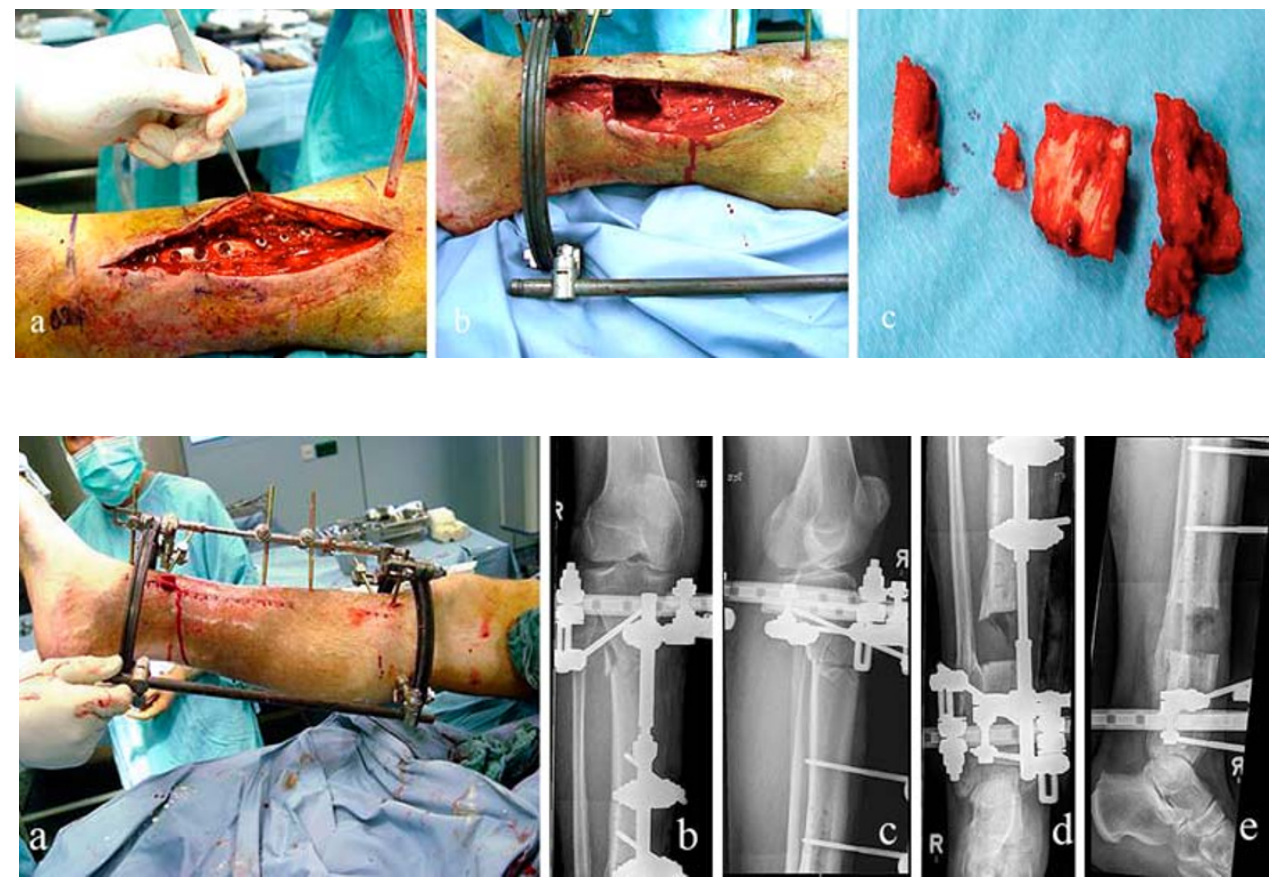


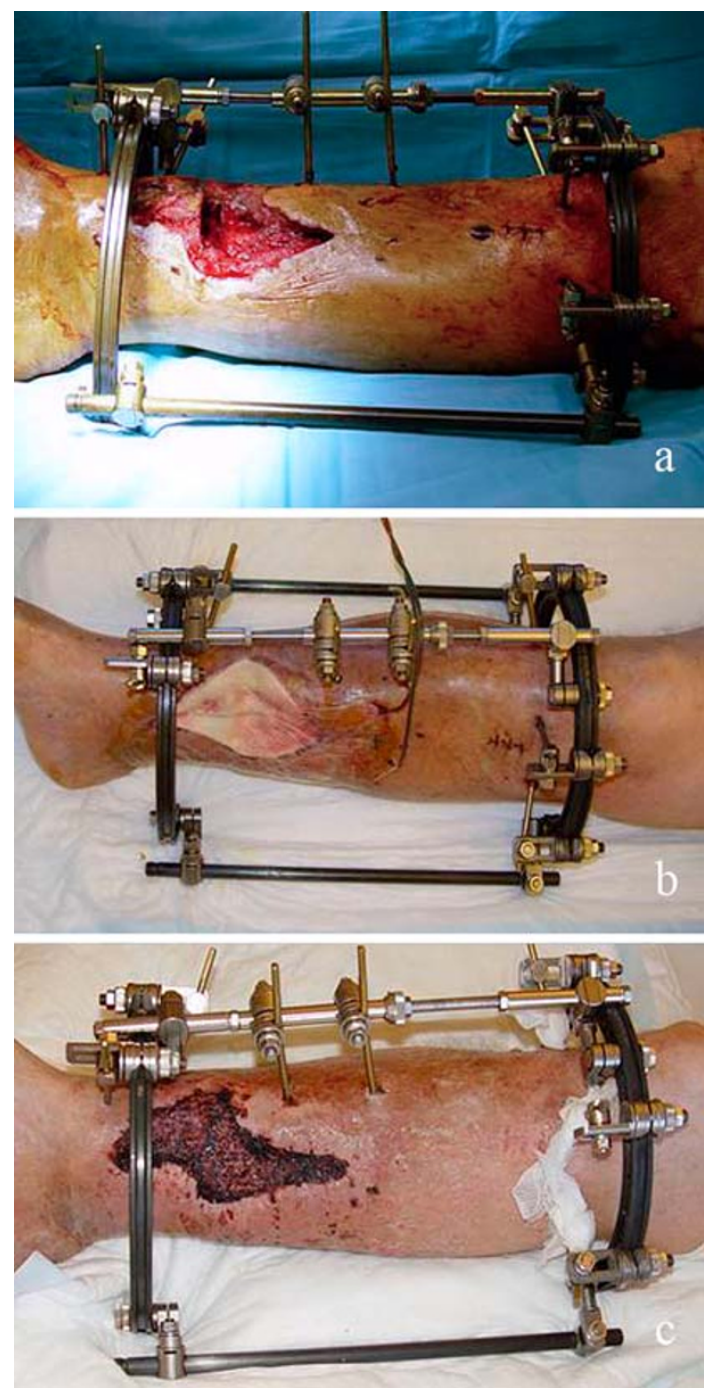

Fig. 5 a Critical soft tissue situation one week after the initial operation. Local treatment with repetitive debridement, lavage and vacuum sealing. Continuation of the transport as an open transport. b Advancing consolidation of the soft tissue. Continuation of the transport. c Consolidated soft tissue. Coverage with mesh graft. Transport completed

dealt with. In his 2002 study Schmidt recommended a ring fixator (the Ilizarov-fixator) as the appropriate tool for bone stabilisation especially if reconstruction was planned for acute purulent bone infections, extended bone defects or a combination of these problems [29]. The main advantage of a ring fixator is the ability to perform three-dimensional reconstruction. We support its use for the stabilisation of the lower leg (tibia) and the forearm. In general it may also be utilised for the treatment of the thigh (femur), but due to the discomfort to the patient, most circular fixators in the thigh are modified to a hybrid fixator. For the upper arm a unilateral fixator will usually be sufficient.

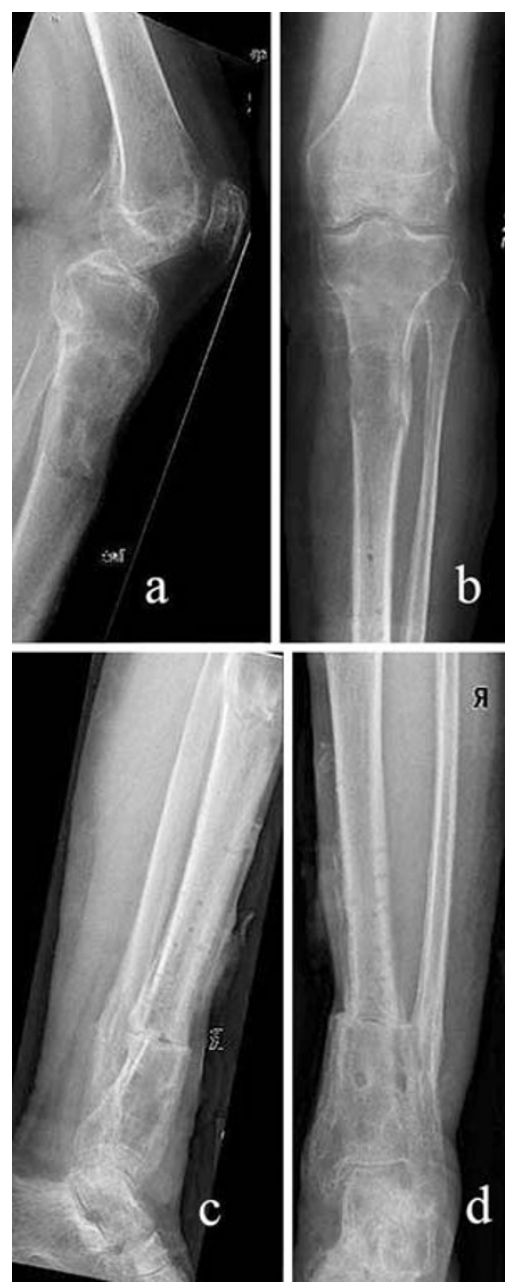

Fig. 6 a, b X-ray after 9 months. The transport is finished and the external fixator is removed. Good callus formation in the transport zone. c, d X-ray of the docking zone after 9 months. It shows almost complete consolidation. Owing to the soft tissue conditions, the docking manoeuvre was carried out as a compression docking without additional plating or cancellous bone graft

Local antibiotic therapy/systemic antibiotic therapy/supportive therapies

The use of local antibiotics such as Gentamycin PMMA beads or Sulmycin sponges are currently the subject of debate. At the beginning of the 1980's the use of local antibiotics were considered essential and indeed were a "sine qua non". However, the rate of Gentamycin resistant microorganisms isolated from osteomyelitic foci has been rising and the use of these supplements is not viewed in a positive light today [30]. Korkusuz et al. [31] are working with special polymers which may be useful as carriers in the local treatment of osteomyelitis. The evidence for use of local antibiotics is not strong. We recommend their use when 

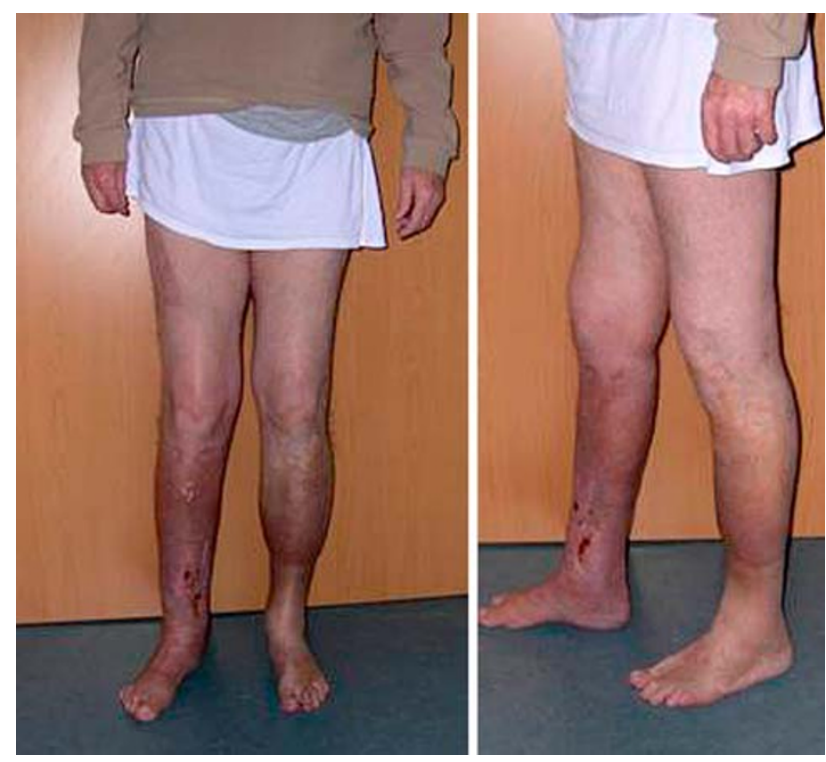

Fig. 7 Clinical examination after 9 months. The soft tissue is consolidated and full weight-bearing of the right leg. No further signs of bone or soft tissue infection

1. an acute purulent osteitis is treated;

2. an acute exacerbation of a chronic osteitis is treated.

Supportive systemic antibiotics may be helpful. To establish optimal efficiency, antibiotic treatment should depend on the results of microbiological investigation of material from the infected focus. Systemic antibiotic treatment is also only necessary in the acute purulent, septic stage of the disease. The long-term application of antibiotics should be considered very critical, not the least because of well-known side effects (e.g. pseudomembranous colitis).

\section{Reconstruction of the soft tissue}

Soft tissue and bone reconstruction should not be looked at as separate procedures. Only complete and good quality soft tissue coverage ensures the survival of newly formed callus. The treatment of the soft tissue must always be considered when planning the first surgical steps to eradicate an osteomyelitic focus. Depending on the size of the soft tissue defect, the spectrum of treatment options ranges from mesh-split skin graft to free vascularised myocutaneous flaps. According to Heppert, soft tissue coverage options will depend on the following criteria [32]:
a. The type of osteosynthesis;
b. The position and size of the soft tissue defect;
c. The local vascular status;
d. Patient compliance.

It is important to plan the reconstruction of soft tissue and skin at an early stage of the treatment so that there is a coordinated strategy with subsequent surgical procedures. For example, a misplaced ring fixator may make satisfactory closure of a soft tissue defect impossible through having the fixator wires exactly in the position where the anastomosis of a free myocutaneous flap has to be located.

\section{Reconstruction of the osseous defect zone}

Many different techniques are available for the bridging of osseous defects. Two of them are well established:

\section{Cancellous bone graft}

This is the oldest known technique for reconstructing a bone defect. A literature review did not indicate a threshold beyond which callus distraction should be used in preference to cancellous bone graft. Different authors have suggested different sizes. For example Schmidt et al. [15] and Schieker et al. [33] proposed $3 \mathrm{~cm}$ as the critical size, while other authors judged $4 \mathrm{~cm}$ to be the ultimate bone defect that may be bridged by a cancellous bone graft [34]. In 2000 Masquelet reported on a series of 35 cases of large diaphyseal bone defects reconstructed by autologous bone grafting. The size of the defects varied between 4 and $25 \mathrm{~cm}$ [34].

The prerequisites for successful use of this technique are:

a. infection-free soft tissue coverage round the osseous lesion;

b. optimal vascular situation in soft tissue and bone;

c. optimal contact between cancellous graft and living cancellous bone.

These conditions are sometimes difficult to achieve especially when treating osteitis. We recommend the use of cancellous bone graft in cases where the diaphyseal bone defect is not bigger than $4 \mathrm{~cm} \mathrm{[35].}$

\section{Callus-distraction}

The callus-distraction technique is today the gold standard for the bridging of osseous defects, especially if the defect is bigger than $4 \mathrm{~cm}$. The technique is based on the findings of Ilizarov [36]. This technique is effective and has many advantages over other methods but requires extensive experience [29].

Many different techniques for callus distraction have been described [29, 37, 38]. These techniques vary and can be based on monorail, unilateral fixators, hybrid fixators and ring fixators. The segmental transport technique during callus distraction may be done externally via pins or internally via one or two cables, and may be carried out in an open or in a closed technique. Each technique has its 
own specific advantages and disadvantages in terms of stability, secondary soft tissue reconstruction and range of motion of the affected limb.

Canadell summarises the advantages of callus distraction as follows [39]:

a. Bone formation in the distraction zone is autogenic and spontaneous;

b. A single low risk surgical procedure is performed;

c. Deformity correction is attainable;

d. Other problems can be treated concurrently;

e. The method of osteosynthesis is stable enough to allow early limb loading; it is adjustable during the course of treatment;

f. Patients can be monitored as outpatients.

The local soft tissue situation influences how the bridging procedure will be carried out: For a closed soft tissue envelope with no infection, good vascularity and correct length of the extremity, callus distraction by closed segmental transport is suitable. If there is a closed soft tissue envelope with no infection, good vascularity but primary shortening of the extremity, then callus distraction by closed segment transport combined with simultaneous soft tissue distraction is preferable. In contrast, if there is an open wound with primary shortening of the extremity and difficulty with primary soft tissue coverage, then we recommend callus distraction and open transport, with the soft tissue coverage performed as a secondary procedure.

\section{Hyperbaric oxygenation}

This is achieved when a patient breathes pure oxygen in an environment with elevated atmospheric pressure. The biochemical body reactions are based on three physical principles:

- Boyle and Mariotte's principle

- Dalton's principle

- Henry's principle

Based on these principles, there is an increase in the plasma volume fraction of transported oxygen which is available for cellular metabolism. There are a number of beneficial physiological effects which result from using hyperbaric oxygenation in the treatment of chronic wounds as well as chronic osteitis. When treating chronic wounds hyperbaric oxygenation is successful in locations with chronic oxygen deficit, i.e. low local oxygen partial pressure. According to the UHMS-Classification chronic and therapy resistant osteitis are verified indications for the use of hyperbaric oxygenation (Table 1) [40]. The negative effect of hypoxia on osteoblasts and osteoclasts and the synergistic effect of hyperbaric oxygen and antibiotic therapy are accepted today [41, 42]. Although animal
Table 1 Indications for hyperbaric oxygen therapy [Greensmith]

- Air or gas embolism

- Carbon monoxide poisoning

- Clostridial myositis and myonecrosis (gas gangrene)

- Crush injury, compartment syndrome, or acute traumatic peripheral ischaemia

- Decompression sickness

- Enhancement of healing in select problem wounds

- Expectional blood loss anaemia

- Intracranial abscess

- Necrotizing soft tissue infections

- Osteomyelitis (refractory)

- Delayed radiation injury (soft tissue and bony necrosis)

- Skin flaps and grafts (compromised)

- Thermal burns

experiments and human case series suggest the benefits of hyperbaric oxygen therapy and recent randomised, prospective studies on trauma patients have supported its efficacy [43], on the 24 February 2000 the German Commission of Medical Doctors and Health Insurances came to the conclusion that there is no evidence of any benefit in the use of hyperbaric oxygenation for the treatment of (chronic) osteitis [44]. An online literature research between 24 February 2000 and 31 March 2007 led to the conclusion that the use of hyperbaric oxygenation as a tool in the therapy of (chronic) osteitis is not evidence-based [44].

\section{Conclusion}

The treatment of osteitis should be targeted specifically at the radical ablation of the osteitic osseous focus and the infected soft tissue with subsequent reconstruction of bone and soft tissues. Current treatment does not depend on surgery alone but on the combination of surgery, antibiotics and supportive methods. Treatment of bone infections, especially when complex reconstructive surgery is needed, should only be undertaken in specialised hospitals where the treatment is done frequently and routinely, where the methods, pitfalls and solutions are well known, and where the experience of the surgeons allows them to overcome difficult problems.

\section{References}

1. Simon C, Stille W (1997) Antibiotikatherapie in Klinik und Praxis. 9. Auflage, Schattauer, Stuttgart 
2. Schnettler R, Steinau HU (2004) Septische Knochenchirurgie. Thieme Verlag. ISBN 3-13-116981-8

3. Hofmann G, Gonschorek O, Hofmann GO, Bühren V (1997) Stabilisierungsverfahren bei Osteomyelitis. Osteosyn Intern 5:226-231

4. Cierny III G, Mader JT, Penninck JJ (1985) A clinical staging system for adult osteomyelitis. Contemp Orthop 10:17-37. Reprint in: Clinical Orthop and Rel Res (2003), (414):7-24

5. Hendrich C, Frommelt L, Euler J (2004) Septische Knochen- und Gelenkchirurgie. Springer Verlag. ISBN 3-540-21341-4

6. Coles CP, Gross M (2000) Closed tibial shaft fractures: management and treatment complications. A review of the prospective literature. Can J Surg 43:256-262

7. Ostermann PA, Seligson D, Henry SL (1995) Local antibiotic therapy for severe open fractures. A review of 1085 consecutive cases. J Bone Joint Surg Br 77:93-97

8. DeLong WG, Born CT, Wei SY, Petrik ME, Ponzio R, Schwab CW (1999) Aggressive treatment of 119 open fracture wounds. J Trauma 46:1049-1054

9. Kindsfater K, Jonassen EA (1995) Osteomyelitis in grade II and III open tibia fractures with late debridement. J Orthop Trauma 9:121-127

10. Ehrenberg JP (1996) GAK. Fractuur statisticken. In: Taurolidine in treatment of experimental post-traumatic osteomyelitis. CIPData Koniklijkse Bibliotheken Den Haag

11. Schwameis E, Abdolvahab F, Wurnig C (1996) Osteomyelitis. Radiologe 36:823-833

12. ittel KK, Weise K (2003) Komplikationsmanagement in der Traumatologie. Georg Thieme Verlag. ISBN 3-13-129161-3

13. Mader JT, Cripps MW, Calhoun JH (1999) Imaging of spine and spinal cord. Raven, New York, pp 278-289

14. Haas DW, Mc Andreaw MP (1996) Bacterial osteomyelitis in adults: envolving considerations in diagnosis and treatment. Am J Med 101:550-561

15. Schmidt HGK, Kranz HW, Siebert Ch (1997) Die Behhandlung von langstreckigen Infekt-Defekt-Pseudarthrosen mit Segmenttransport im Ringfixateur. Osteosyn Intern 5:212-220

16. Kälicke T, Kutscha-Lissberg F, Frangen TM, Muhr G, Arens S (2004) Pathophysiologie der posttraumatischen Osteitis. Orthopäde 33:404-411

17. Tsukayama DT (1999) Pathophysiology of posttraumatic osteomyelitis. Clin Orthop 360:22-34

18. Simpson AHRW, Deakin M, Latham JM (2001) The effect of the extent of surgical resection on infection-free survival. J Bone Joint Surg Br 81:1046-1050

19. Abe E, Yen K, Okada K (2000) Pyogenic vertebral osteomyelitis presenting as a single spinal compression fracture: a case report and review of the literature. Spinal Cord 38:639-644

20. Lehovsky J (1999) Pyogenic vertebral osteomyelitis/disc infection. Baillieres Clin Rheumatol 13:59-75

21. Schauwecker D (1992) The scintigraphic diagnosis of the osteomyelitis. AJR 158:9-18

22. Even-Saphir E, Martin RH (1994) Degenerative disc disease: a cause for diagnostic dilemma on In-111 WBC studies in suspected osteomyelitis. Clin Nucl Med 19:338-392

23. Guhlmann A, Storck M, Kotzerke J, Moog F, Sunder-Plassmann L, Reske SN (1997) Chronic osteomyelitis. Detection with FDG PET and correlation with histopathologic findings. Radiology 206:749-754
24. Robiller FC, Stumpe KD, Kossmann T, Weishaupt D, Bruder E, von Schulthess GK (2000) Chronic osteomyelitis of the femur: value of PET imaging. Eur Radiol 10:855-858

25. Neugebauer C, Graf R (2004) Gutachterliche Probleme bei der Beurteilung von Osteomyelitiden. Orthopäde 33:603-613

26. David A, Richter J, Köller M, Muhr G (1997) Therapie der frühen Infektion nach Osteosynthese. Osteosyn Intern 5:232-235

27. Liener U, Kienzl L (1997) Die Behandlung der posttraumatischen Osteomyelitis. Osteosyn Intern 5:193-198

28. Kutscha-Lissberg F, Hebler U, Kälicke T, Arens S (2004) Prinzipien chirurgischer Therapiekonzepte der postoperativen und chronischen Osteomyelitis. Orthopäde 33:439-454

29. Schmidt HGK, Wurm M, Halder D, Grosser V (2002) Verlängerungstechniken und Möglichkeiten des Segmenttransportes im Ringsystem nach Ilizarov. Trauma und Berufskrankh 4:413-426

30. Alonge TO, Wale A (1999) Intraoperative antibiotic bead maker: point of technique. Afr J Med Sci 28(3-4):193-194

31. Korkusuz F, Korkusuz P, Gursel I, Hasirici V (2001) In vivo response to biodegradable controlled antibiotic release systems. J Biomed Mater Res 55(2):217-228

32. Heppert V, Glatzel U, Wentzensen A (2004) Postoperative und bakterielle Osteitis. Orthopäde 33:316-326

33. Schieker M, Mutschler W (2006) Die Überbrückung von posttraumatischen Knochendefekten. Unfallchirurg 109:715-732

34. Masquelet AC, Fitoussi F, Begue T, Muller GP (2000) Reconstruction of the long bones by the induced membrane and spongy autograft. Ann Chir Plast Esthet 45(3):346-353

35. Tiemann AH, Braunschweig R, Hofmann GO (2008) Kontinuitätserhalt oder Segmentresektion: Entscheidungshilfen bei der Sanierung der Osteitis am Schaft langer Röhrenknochen. Trauma und Berufskrankheit. doi:10.1007/s10039-008-1441-6

36. Ilizarov GA (1992) Transosseous osteosynthesis. Springer, Berlin, pp 137-256

37. Baumgart R, Hinterwimmer S, Krammer M, Mutschler W (2004) Bone transport system with central cable- fully automatic, continuous distraction osteogenesis for the treatment of large bone defects. Biomed Tech 49:202-207

38. Weber U (1998) Segmenttransport des Knochens mittels Kabelrollen und fexibelem Draht-eine neue Technik am Ringfixateur. Med Orthop Tech 118:134-140

39. Canadell J, Forriol F (1997) The external fixator in the treatment of infected pseudarthrosis and bone defect. Osteosyn Intern 5:221-225

40. UHMS (1999) Hyperbaric oxygen therapy 1999. Committee report. Undersea \& Hyperbaric Medical Society, Kensington

41. Mendel V, Reichert B, Simanowski HJ, Scholz HC (1999) Therapy with hyperbaric oxygen and cefazolin for experimental osteomyelitis due to Staphylococcus aureus in rats. Undersea Hyperbar Med 26:169-174

42. Park MK, Muhvich KH, Myers RAM, Marzella L (1991) Hypoxia prolongs the aminoglycoside-induced post-antibiotic effect in Pseudomonas aeruginosa. Antimicrob Agents Chemother 35:691-695

43. Greensmith JE (2004) Hyperbaric oxygen therapy in extremity trauma. J Am Acad Orthop Surg 12(6):376-384

44. Tiemann AH, Diefenbeck M, Mückley T, Hofmann GO (2008) Hyperbare Sauerstofftherapie in der Osteitisbehandlung-Gibt es Neuigkeiten? Zentralblatt für Chirurgie 133:396-398 